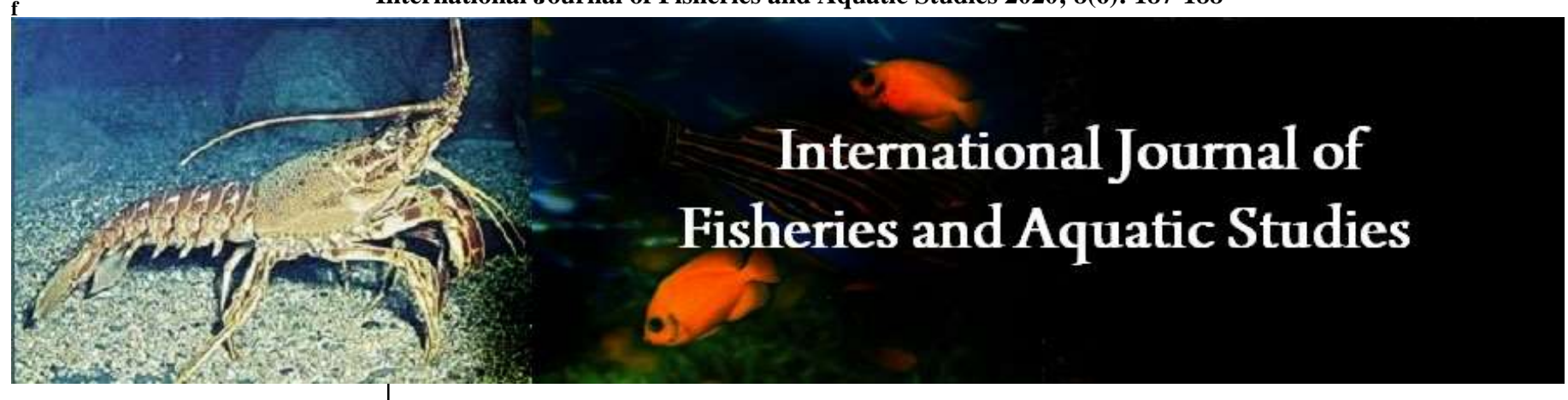

E-ISSN: 2347-5129

P-ISSN: 2394-0506

(ICV-Poland) Impact Value: 5.62

(GIF) Impact Factor: 0.549

IJFAS 2020; 8(6): 187-188

(C) 2020 IJFAS

www.fisheriesjournal.com

Received: 06-09-2020

Accepted: 16-10-2020

Madhu Sharma

Department of Fisheries,

COVAS, CSKHPKV, Palampur,

Himachal Pradesh, India

Jyoti Thakur

Department of Zoology, CUHP,

Dharmshala, Himachal Pradesh, India

\section{Effect of oxytetracyclin on behavior of fish Cyprinus carpio}

\author{
Madhu Sharma and Jyoti Thakur
}

DOI: https://doi.org/10.22271/fish.2020.v8.i6c.2376

\section{Abstract}

The present study was designed to assess the toxic effect of antibiotic oxytetracyclin (OTC) in fish Cyprinus carpio using behavior changes as a biomarker. The acute exposure was given up to 96 hours of treatment. Sub-lethal concentration used in the experiment was $80 \mathrm{mg} / \mathrm{l}$ of water. Change in behavior pattern was observed after 24, 48, 72 and 96 hours of exposure. Different behavioural alteration like, high pigmentation, high mucus secretions, loss of equilibrium, hyperactivity were seen throughout the exposure. The behavioural changes become more severe with increase in time duration.

Keywords: Behaviour alterations, toxicity, antibiotics, oxytetracyclin

\section{Introduction}

OTC is widely used broad spectrum antibiotic belonging to class tetracycline ${ }^{[1]}$. In a world market of pharmaceuticals India has emerged as one of the top five pharmaceuticals market ${ }^{[2]}$. Production of pharmaceuticals is rising at $14 \%$ per year. This may be due to excise duty free zone for pharmaceutical manufacturing done by the Central and State Governments of India leading to large scale production of pharmaceutical. Moreover deliberate discharge and accidental release of non biodegradable by-products either untreated or partially treated waste to environment further deepen the problem of pharmaceutical pollution in aquatic ecosystems and has the potential to disrupt the structure and functioning of natural ecosystems. OTC has high hydrophilic characters and low volatization and significantly persistent in water ${ }^{[3]}$.

Bioassay based on behavior is faster, more sensitive and ecologically more relevant as assessing growth and reproduction need longer bioassay. Behavioural bioassay is more promising alternatives than lethality evaluating bioassay which are currently used for the risk assessment of toxicant. Behavioural changes provide early warning signals about the health of exposed population which other standard tests do not take in to consideration ${ }^{[4]}$. Fish are very sensitive to even minute quantities of pollutants so can be considered sentinels of slight perturbation in the environment. Furthermore, fish is a good indicator of toxicity studies due to its position in food web ability to bio-accumulate toxicants sensitivity to low concentration of pollutant and nutritive value to human ${ }^{[5]}$. Fish Cyprinus carpio was used for the experiment. So the present study was designed to study the toxic effect of oxytetracyclin on behavior of fish.

\section{Materials and Methods}

Fish Cyprinus carpio taken from the Fish farm of Department of Fisheries, DGCN COVAS, CSKHPKV, Palampur H. P. were used for the experiment. The chosen fish were of total length $23.5 \pm 17 \mathrm{~cm}$ and total weight of $160 \pm 60 \mathrm{~g}$. The antibiotic oxytetracyclin immersion was taken from the local medical store. Exposure was semi-static and every 24 hours the drug was replenished to complete the initial concentration. The experimental glass aquaria were of 100 liters capacity each. Control animal were submitted to the same water change schedule without the addition of OTC. Exposure was given for 96 hours. Sub-lethal concentration of OTC was decided as $80 \mathrm{mg} / \mathrm{l}$ of water for the exposure according to the $\mathrm{LC}_{50}$ value for $C$. carpio of Ambili ${ }^{[6]}$. Behavioural alterations were observed after 24, 48, 72 and 96 hours of exposure from both treated as well as control groups.

Behavioural inconsistencies were keenly observed in both the groups (Control and treated) for hyperactivity, movement, equilibrium, opercula movement, pigmentation, respiratory rate, 
air gulping, jumping, mucus secretion, aggressiveness, motionless, vertical movement, surfacing.

\section{Results}

Control or untreated fish exhibited normal behavior like a normal rate of swimming, mild opercular movement, responding to low stimulus during the experiment. On the other hand fish exposed to OTC, significant changes in behavious were observed. As the fish were placed in the exposure medium they immediately move to the corner of the tank. But after a few hours they become mild hyperactive and move separately in the tank. After 24 hours of the exposure, mild increase in pigmentation was observed and a layer of mucus was also seen on the body surface. With increase in duration of exposure surfacing behavior was observed along with hyperventilation, loss of equilibrium, high pigmentation, thick layer of mucus, very less movement and lost response to external stimuli (Table-1). At the highest hour of exposure pigmentation, loss of equilibrium, mucus secreation and surface gulfing was more pronounced.

Table 1: Different behavioural changes observed in fish C. carpio after exposure with $80 \mathrm{mg} / \mathrm{liters}$ of Oxytetracyclin.

\begin{tabular}{|c|c|c|c|c|c|c|c|}
\hline S. No. & Parameters & Control & 24 hrs 48 hrs & $\mathbf{7 2}$ hrs 96 hrs \\
\hline 1 & Hyperactivity & - & + & ++ & ++ & ++ \\
\hline 2 & Operculum movement & + & -- & ++ & ++ & ++ \\
\hline 3 & Rate of swimming & + & -- & + & ++ & ++ \\
\hline 4 & Corner behaviour & - & +++ & - & - & - \\
\hline 5 & Pigmentation & - & + & +++ & +++ & +++ \\
\hline 6 & Mucus secretion & - & + & ++ & ++ & ++ \\
\hline 7 & Loss of balance & - & - & - & + & ++ \\
\hline 8 & Surface gulfing & - & - & + & +++ & +++ \\
\hline
\end{tabular}

(-) None, (+) mild, (++) Moderate, (+++) Strong

\section{Discussion}

Behaviour analysis may be considered as a robust and sensitive tool for detecting acute exposure of chemical to fish [7]. Behavioural alterations may be a protective mechanism of fish to avoid unsuitable conditions for some time or may be toxic damage to the nervous system. In the present study the locomotor response of fish was sensitive to OTC as observed by alteration in the swimming pattern of fish. Alteration of locomotion behavior is very often linked with neurological impairment. Tetracyclins have been associated with cranial nerve toxicity and neuromuscular blockage ${ }^{[8]}$. Respiratory distress observed may be due to increase in metabolic demand of fish. Decline in swimming activity with increase in exposure time may be a result of the increase demand of glycogen to meet the stressful condition. Aquatic surface respiration was observed at later hour of exposure due to enhanced oxygen demand due to hypoxic condition. Excessive mucus secreation found in fish is to make a protective layer around the body to reduce the body contact toxic environment and get relief from irritation caused by pollutant ${ }^{[9]}$. A high pigmentation was observed, which suggests that OTC dysfunction the pituitary gland and influence the distribution of chromatophores [10]. Previous studies have revealed that a number of chemicals can provoke abnormal behavior in fish ${ }^{[9,11]}$. Several studies have reported similar results in fish with response to pharmaceuticals ${ }^{[12]}$.

\section{Conclusion}

The results of the present show that OTC has a strong influence on behavior of $\mathrm{C}$. carpio and contribute to sound assessment of environmental hazards posed by this antibiotic.

\section{Acknowledgments}

The authors are thankful to Dean College of Veterinary and Animal Sciences, for providing laboratory facility.

\section{References}

1. Li W, Shi Y, Gao L, Liu J, Cai Y. Occurrence of antibiotics in water, sediments, aquatic plants, and animals from Baiyangdian Lake in North China. Chemosphere 2012;89(11):1307-1315

2. Chander V, Sharma B, Negi V, Aswal RS, Singh P, Singh $\mathrm{R}$, et al. Pharmaceutical Compounds in Drinking Water. Journal of Xenobiotics 2016;6(1):5774. http.doi: 10.4081/xeno.2016.5774

3. Daghrir R, Drogui P. Tetracycline antibiotics in the environment: a review. Environmental Chemistry Letters 2013;11(3):209-227.

4. Sharma M, Chadha P, Borah MK. Fish behaviour and immune response as a potential indicator of stress caused by 4-nonylphenol. American Journal of Biosciences 2015;3(6):278-283.

5. Sharma M, Chadha P. Immunological impairment as a marker of 4-nonylphenol induced stress. Indian Journal of Animal Sciences 2019;89(6):695-698, June 2019/Article

6. Ambili TR, Saravanan M, Ramesh M, Abhijith DB, Poopal RK. Toxicological effects of the antibiotic oxytetracycline to an Indian major carp Labeo rohita. Archive of Environmental Contamination and Toxicology 2013;64(3):494-503. doi: 10.1007/s00244-012-9836-6. Epub 2012 Nov 29.

7. Gaaied S, Oliveira M, Domingues I, Banni M. 2,4Dichlorophenoxyacetic acid herbicide effects on zebrafish larvae: development, neurotransmission and behavior as sensitive endpoints. Environmental Science and Pollutition Research 2019; https://doi.org/10.1007/s11356-019-04488-5

8. Thomas RJ. Neurotoxicity of antibacterial therapy. Southern Medical Journal 1991;87:869-74.

9. Sharma M. Behavioural responses in effect to chemical stress in fish: A review. International Journal of Fisheries Aquatic Studies 2019;7(1):01-05.

10. Harit G, Srivastava N. Behavioural alterations in Channa punctatus after exposure to endosulfan followed by subsequent recovery. International Journal of Fisheries and Aquatic Studies 2018;6(2):51-55

11. Altenhofen S, Wiprich MT, Nery LR, Leite CE, Vianna MR, Bonan CD, et al. Manganese(II) chloride alters behavioral and neurochemical parameters in larvae and adult zebrafish. Aquatic Toxicology 2017;182:172-183. https://doi.org/10.1016/j.aquatox.2016.11.013

12. Almeida AR, Tacão M, Machado AL, Golovko O, Zlabek $\mathrm{V}$, Domingues I, et al. Long-term effects of oxytetracycline exposure in zebrafish: A multi-level perspective. Chemosphere 2019;222:333-344. 